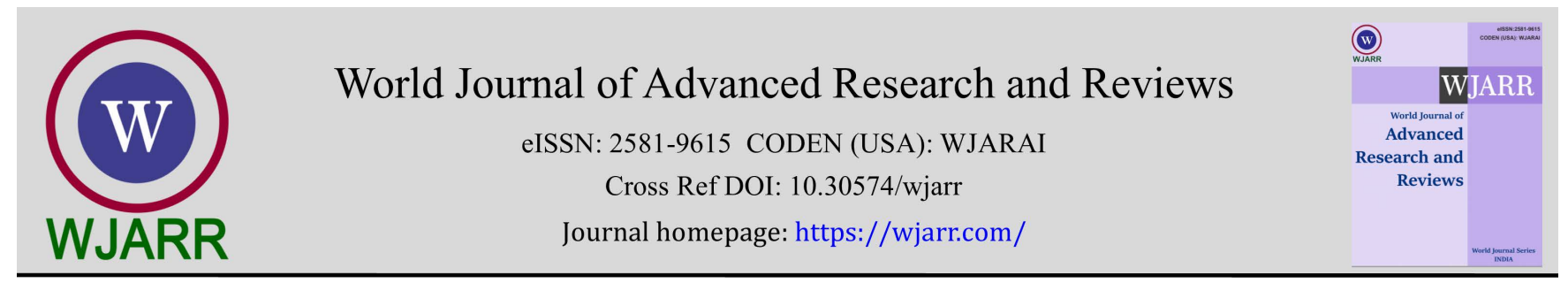

(RESEARCh ARTicle)

Check for updates

\title{
Quality of life of CKD patients with routine hemodialysis in Haji Adam Malik Hospital Medan
}

\author{
Sihombing JP $1{ }^{*}$, Nasution AT ${ }^{2}$ and Sitanggang $\mathrm{H}^{1}$ \\ ${ }^{1}$ Department of Pharmacy, Poltekkes Kemenkes Medan, Indonesia. \\ ${ }^{2}$ Hemodialysis Unit Haji Adam Malik Hospital Medan, Indonesia.
}

World Journal of Advanced Research and Reviews, 2021, 10(01), 289-295

Publication history: Received on 16 March 2021; revised on 20 April 2021; accepted on 22 April 2021

Article DOI: https://doi.org/10.30574/wjarr.2021.10.1.0170

\begin{abstract}
Objective: To elicit quality of life of chronic kidney disease (CKD) patients with routine hemodialysis receiving erythropoietin from clinical and humanistic outcome, to analysis characteristic factors to Hb, fatique and the quality of life (QOL) of CKD patients with routine hemodialysis, and to explore the change in QOL over one month for patients managed in the hospitals.

Methods: A prospective study was conducted among adult CKD patients in Haji Adam Malik Hospital Medan. QOL was measured using kidney disease quality of life - short form (KDQOL-SFTM) questionnaire and FACIT fatigue scale questionnaire. CKD patients. Patients were asked to complete the KDQOL-SFTM questionnaire and FACIT fatigue scale questionnaire two times in one month range.
\end{abstract}

Results: Average rate of haemoglobin was increased after one month anemia treatment using erythropoietin 8.68: 8.82. Average rate of FACIT was increased after one month anemia treatment using erythropoietin 43.98: 44.81. Average rate of KDQOL was increased after one month anemia treatment using erythropoietin 76.83: 77.94.

Conclusion: Erythropoietin can improve QOL of CKD patients with routine hemodialysis.

Keywords: CKD; Hemodialysis; QOL; Erythropoietin

\section{Introduction}

CKD prevalence in all over the world predicted to reach $16 \%$ of populations. CKD incidence rises every year especially in developing countries cause of increasing life expectation age so that people has a longer age. CKD therapy needs special treatment such as dialysis (hemodialysis or peritoneal dialysis) or renal transplantation which needs a lot of costs. Renal transplantation actually is more efficient compared to dialysis because only in one treatment can make patients avoid dialysis procedure which takes place in relatively long duration. Meanwhile, many people use dialysis to treat CKD doe to renal transplant availability [1].

One of CKD complication is anemia. Anemia is common in CKD patients especially if glomerular filtration rate (GFR) < $60 \mathrm{ml} / \mathrm{min}$ and almost all CKD patients have anemia if GFR $<27 \mathrm{ml} / \mathrm{min}$. It also said that almost $50 \%$ CKD stage $3-4$ patients have anemia and increase almost $75 \%$ in end-stage renal disease (ESRD) [2].

\footnotetext{
${ }^{*}$ Corresponding author: Sihombing JP

Department of Pharmacy, Poltekkes Kemenkes Medan, Indonesia.

Copyright $(2021$ Author(s) retain the copyright of this article. This article is published under the terms of the Creative Commons Attribution Liscense 4.0.
} 
Most of anemia in CKD occured by the decrease of erythropoietin (EPO) production. It can also because of inadequate of blood iron, inadequate of nutrition, inflammation, hyper parathyroid, excessive loss of blood, etc. Non-treated anemia can make fatigue, decrease the ability of physical activity, cognitive function, immune response and decrease the quality of life that can increase morbidity and mortality [3].

Anemia of EPO deficiency can be treated by EPO delivery, red cell transfusion or both. Most of that is by EPO delivery. The earlier research said that EPO delivery can decrease transfusion and increase patient's QOL compare with nondelivery EPO [4]. Another study reported that total cost of anemia treatment in CKD patients with hemodialysis is cheaper with transfusion compare with EPO delivery but patient's QOL is better by EPO delivery compare with transfusion [5].

Erythropoietin is an essential growth factor for erythroid progenitor cells, which produced mainly in the kidney [6]. Short-acting erythropoietin-stimulating agents (ESAs) that have been used for the treatment of renal anemia such as erythropoietin alpha and erythropoietin beta have a half-life of 6-8 h when given intravenously and a half-life of 19-24 $\mathrm{h}$ when given subcutaneously, but more effective when administered subcutaneously. Long-acting ESAs such as darbepoetin alpha and CERA have a half-life 2-3 times than short-acting ESAs. In Indonesia, there are only short-acting ESAs used for the treatment of renal anemia.

WHO define the QOL as a multiple dimensions concept that concerns an individual's usual or expected physical, emotional and social well-being. It will describe the design, assessment, analysis and interpretation of single and multiitem, subjective measurement scales. The broad definition will include scales or instruments that ask general questions, such as "in general, how would you rate your health now?", and more specific questions on particular symptoms and side effects, such as "during the past week have you felt nauseated?" This measurement scales all have the common feature of using a standardized approach to assessing a person's perception of their own health by using the numerical scoring system and may include one or several dimensions of QOL [7].

There are some instruments to measure fatigue scale. One of them is Functional Assessment Chronic Illness Therapy (FACIT) Fatigue Scale which was validated by Cella, et al. (2005) [8]. It said that FACIT-Fatigue Scale is a brief, valid measure for monitoring important symptom and its effects on chronic illness. FACIT-Fatigue Scale consists of thirteen questions and easy to use to measure individual fatigue scale during their daily activities in last one week [9]. FACITFatigue Scale is a collection of health-related quality of life questionnaires targeted to management of chronic illness by measuring body functional system [10]. This makes us know the relation of fatigue with QOL. FACIT Fatigue Scale had been translated in Indonesian and validated by Sihombing et al. (2016) [11].

\section{Material and methods}

We conducted a prospective study of CKD patients with routine hemodialysis from Haji Adam Malik Hospital Medan from Aug 2020 - Oct 2020. Participants were eligible if they were CKD patients with routine hemodialysis at least in 3 months, aged from 20 - 80 years and use EPO to treat their anemia. Participants with a current functioning kidney transplant or diagnosed with cancer were excluded. Using patient database we used purposive sampling to capture a range of demographic and clinical characteristics including age, gender, ethnicity, work status, employment, and kind of EPO used.

Ethical approval was obtained from ethics committee Politeknik Kesehatan Kemenkes Medan with reference number 01.598/KEPK/POLTEKKES KEMENKES MEDAN 2020. Patient's approval was obtained by using informed consent forms. The surveys were administrated face to face and participants can answer the questions his/herself or with their family.

Sociodemographic and clinical information were collected from patient's medical records. The participants were asked to value their current health using KDQOL-SF and FACIT-Fatigue scale. They were asked to rate their health where QOL was measured on a scale from 0 (least preferred health state) to 100 (perfect health with no kidney disease). They were also asked to rate their fatigue scale from 0 (fatigue very much) to 4 (not fatigue at all).

Participants then completed the FACIT-Fatigue scale and KDQOL-SF questionnaire, a multidimensional, reliable and validated instrument developed for dialysis patients. They completed the questionnaire two times in approximate onemonth range. The KDQOL includes the SF-36 health survey as its generic core measuring 8 domains such as physical functioning, role limitation physical, role limitation emotional health, energy(vitality), emotional well-being, social functioning, pain, and general health perception; augmented with multi-scale targeted at CKD-specific concerns 
(symptoms and problems, effect of kidney disease, burden of kidney disease, work status, cognitive function, quality of social interaction, sexual function, sleep, social support and dialysis staff).

Descriptive statistics were calculated and reported as a mean \pm standard deviation. Then compare the mean of two groups (patients receive erythropoietin alpha with patients receive erythropoietin beta) by independent sample $t$ test. The analysis was conducted using statistical package for social science (SPSS) 22 version.

\section{Results and discussion}

Fifty three CKD patients with routine hemodialysis from Aug 2020 to Oct 2020 provided baseline data (Table 1). Almost $70 \%$ of patients were male and almost $80 \%$ were in the range of $20-60$ years old.

Table 1 Characteristic CKD patients with routine hemodialysis using Erythropoietin.

\begin{tabular}{|l|l|l|}
\hline Parameter & Total & Percentage (\%) \\
\hline Age (years) & & \\
$20-60$ & 41 & 77.36 \\
$>60$ & 12 & 22.64 \\
\hline Gender & & \\
Male & 36 & 67.92 \\
Female & 17 & 32.08 \\
\hline Status & & \\
Married & 39 & 73.58 \\
Unmarried & 14 & 26.42 \\
\hline Employment & & \\
Work & 38 & 71.70 \\
Not work & 15 & 28.30 \\
\hline Education & & \\
$<$ SHS & 39 & 73.58 \\
UG & 14 & 26.42 \\
\hline
\end{tabular}

After one month anemia treatment using erythropoietin there were increasing the rate of haemoglobin. At the first periode the average rate of haemoglobin was 8.68 while at the second periode (one month later) the average rate of haemoglobin was 8.82. Statistic calculation for rate of haemoglobin shown that compare mean of two groups (patients receive erythropoietin at the first periode with patients receive erythropoietin at the second periode) was not different significantly $(\mathrm{p}=0.423)$.

Table 2 Average $\mathrm{Hb}$ after one month anemia treatment using erythropoietin

\begin{tabular}{|c|c|c|c|c|}
\hline & \multicolumn{2}{|c|}{ Hb (g/dl) } & \multirow{2}{*}{$\Delta$} & \multirow[b]{2}{*}{$\mathbf{p}$} \\
\hline & FP & SP & & \\
\hline EPO & $8.68 \pm 1.63$ & $8.82 \pm 1.64$ & $0.13 \pm 0.95$ & 0.423 \\
\hline
\end{tabular}


The results of FACIT fatigue scale questionnaire in CKD patients with routine hemodialysis $(\mathrm{N}=53)$ were listed in Table 3. At the first period, the average rate of FACIT for CKD patients receive erythropoietin was 43.98 while at the second period (one month later), the average rate of FACIT for CKD patients receive erythropoietin was 44.81. Statistic calculation for rate of FACIT shown that compare mean of two groups (patients receive erythropoietin at the first periode with patients receive erythropoietin at the second periode) was not different significantly $(p=0.081)$.

Table 3 Results of FACIT fatigue scale questionnaire in CKD patients with routine hemodialysis

\begin{tabular}{|c|c|c|c|}
\hline \multirow{2}{*}{ No } & \multirow{2}{*}{ Statement } & \multicolumn{2}{|l|}{ Score } \\
\hline & & $\mathrm{FP}$ & SP \\
\hline HI7 & I feel fatigued & $3.32 \pm 0.87$ & $3.49 \pm 0.64$ \\
\hline HI12 & I feel weak all over & $3.34 \pm 0.83$ & $3.49 \pm 0.64$ \\
\hline An1 & I feel listless (washed out) & $3.34 \pm 0.83$ & $3.45 \pm 0.67$ \\
\hline An2 & I feel tired & $3.38 \pm 0.81$ & $3.42 \pm 0.66$ \\
\hline An3 & $\begin{array}{l}\text { I have trouble starting things because I } \\
\text { am tired }\end{array}$ & $3.53 \pm 0.77$ & $3.55 \pm 0.64$ \\
\hline An4 & $\begin{array}{l}\text { I have trouble finishing things because I } \\
\text { am tired }\end{array}$ & $3.75 \pm 0.68$ & $3.68 \pm 0.58$ \\
\hline An5 & I have energy & $2.36 \pm 0.83$ & $2.58 \pm 0.66$ \\
\hline An7 & I am able to do my usual activities & $2.83 \pm 1.09$ & $2.83 \pm 0.75$ \\
\hline An8 & I need to sleep during the day & $2.36 \pm 1.15$ & $2.51 \pm 0.95$ \\
\hline An12 & I am too tired to eat & $4.00 \pm 0.00$ & $4.00 \pm 0.00$ \\
\hline An14 & I need help doing my usual activities & $3.96 \pm 0.27$ & $3.94 \pm 0.30$ \\
\hline An15 & $\begin{array}{l}\text { I am frustated by being too tired to do } \\
\text { the things I want to do }\end{array}$ & $3.85 \pm 0.57$ & $3.87 \pm 0.42$ \\
\hline An16 & $\begin{array}{l}\text { I have to limit my social activity because } \\
\text { I am tired }\end{array}$ & $3.96 \pm 0.19$ & $3.98 \pm 0.14$ \\
\hline
\end{tabular}

The results of KDQOL-SF questionnaire in CKD patients with routine hemodialysis $(\mathrm{N}=53)$ were listed in Table 4 . At the first period, the average rate of KDQOL-SF for CKD patients receive erythropoietin was 76.83 while at the second period (one month later), the average rate of KDQOL-SF for CKD patients receive erythropoietin was 77.94. Statistic calculation for rate of KDQOL-SF shown that compare mean of two groups (patients receive erythropoietin at the first periode with patients receive erythropoietin at the second periode) was different significantly $(p=0.004)$.

Table 4 Results of KDQOL questionnaire in CKD patients with routine hemodialysis.

\begin{tabular}{|l|l|l|l|}
\hline \multirow{2}{*}{ No } & \multirow{2}{*}{ Domain } & Score & \multicolumn{2}{|l|}{} \\
\cline { 3 - 4 } & & FP & SP \\
\hline & CKD-targeted & & \\
\hline A1 & Symptom/problem & $93.99 \pm 6.71$ & $94.97 \pm 5.73$ \\
\hline A2 & Effect of kidney disease & $92.10 \pm 7.24$ & $92.81 \pm 6.76$ \\
\hline A3 & Burden of kidney disease & $72.52 \pm 24.15$ & $74.41 \pm 22.54$ \\
\hline A4 & Work status & $39.62 \pm 49.38$ & $39.62 \pm 49.38$ \\
\hline A5 & Cognitive function & $71.57 \pm 21.65$ & $74.34 \pm 16.92$ \\
\hline A6 & Quality of social interaction & $82.01 \pm 11.14$ & $84.15 \pm 8.89$ \\
\hline
\end{tabular}


World Journal of Advanced Research and Reviews, 2021, 10(01), 289-295

\begin{tabular}{|l|l|l|l|}
\hline A7 & Sexual function & $29.25 \pm 43.78$ & $28.77 \pm 43.13$ \\
\hline A8 & Sleep & $60.52 \pm 24.79$ & $64.25 \pm 20.24$ \\
\hline A9 & Social support & $98.75 \pm 6.35$ & $98.38 \pm 4.53$ \\
\hline A10 & Dialysis staff encouragement & $100.00 \pm 0.00$ & $100.00 \pm 0.00$ \\
\hline A11 & Patient satisfaction & $51.92 \pm 5.44$ & $51.28 \pm 4.53$ \\
\hline & 36-item health survey & & \\
\hline B1 & Physical functioning & $67.64 \pm 26.10$ & $67.36 \pm 24.27$ \\
\hline B2 & Role-physical & $87.26 \pm 23.83$ & $87.74 \pm 24.33$ \\
\hline B3 & Pain & $88.07 \pm 19.36$ & $88.58 \pm 14.84$ \\
\hline B4 & General health perceptions & $73.79 \pm 19.21$ & $75.98 \pm 15.61$ \\
\hline B5 & Emotional well-being & $89.74 \pm 5.74$ & $90.04 \pm 4.34$ \\
\hline B6 & Role-emotional & $85.53 \pm 20.16$ & $88.05 \pm 19.71$ \\
\hline B7 & Social function & $91.27 \pm 13.78$ & $92.69 \pm 11.35$ \\
\hline B8 & Energy (Vitality) & $84.25 \pm 8.11$ & $86.42 \pm 7.68$ \\
\hline & & & \\
\hline \multicolumn{2}{|c|}{ Mean+SD } &
\end{tabular}

Table 5 Average KDQOL score in CKD patients with routine hemodialysis base on domain.

\begin{tabular}{|l|l|l|l|l|}
\hline \multirow{2}{*}{ DOMAIN } & \multicolumn{2}{|l|}{ EPO } & \multirow{2}{*}{ P } \\
\cline { 2 - 5 } & FP & SP & $\Delta$ & \\
\hline Physical well-being & $75.99 \pm 12.50$ & $76.91 \pm 11.48$ & $0.93 \pm 3.80$ & 0.082 \\
\hline Mental well-being & $85.71 \pm 8.25$ & $87.21 \pm 7.76$ & $1.49 \pm 4.37$ & 0.016 \\
\hline Kidney disease & $69.48 \pm 13.72$ & $71.03 \pm 12.75$ & $1.54 \pm 4.65$ & 0.019 \\
\hline Pasien Satifaction & $75.96 \pm 2.72$ & $75.64 \pm 2.27$ & $-0.32 \pm 1.63$ & 0.157 \\
\hline Average & $76.83 \pm 8.05$ & $77.94 \pm 7.86$ & $1.11 \pm 2.71$ & 0.004 \\
\hline
\end{tabular}

A study about correction of anemia in CKD patients receives erythropoietin alpha reported that there was improvement QOL from baseline values weather in the high-hemoglobin group and in the low-hemoglobin group. It also showed a similar level of improvement from baseline values in both groups, except for the score for emotional role subscale of SF-36, which was significantly higher in the low-hemoglobin group [12]. Other publications deliver such a better QOL due to anemia management with erythropoietin, except for two domains regard to ability to work (work status: 34.7 become 31.7) and role limitation caused by a physical health problem (role physical : 39.7 become 39) [13]. In this study, we also found out that one month from baseline after receiving erythropoietin, CKD patients had better QOL almost in all domains, except in patients satisfaction from 75.96 became 75.64 .

A previous publication reported that fatigue impacts patients' abilities to manage their daily activities and to remember and concentrate on conversations and what is going on around them [14] and feel isolated from others and society [15]. This makes decreasing their participation in even simple physical and mental activities for patients on dialysis. Physical domain was highly affected in CKD patients with hemodialysis [16].

Post-dialysis fatigue patients required almost five hours of sleep to recover and had more depression, insomnia, and body aches than those who did not [17]. They also had a limitation in their functional independence and participation in social activities [18]. Research suggests that fatigue may be part of a symptom complex that includes nausea, muscle cramps, and headache, which may be the result of the fluid shifts that occur during hemodialysis [19]. 
Another study in China that determined same inclusive criteria with this study such as receiving routine hemodialysis for at least three months, being identified as an outpatient, 18 years of age or older and willing to participate and sign written informed consent, gave a total score of FACIT fatigue scale 41 (average 3.15) [20].

Our study has several other limitations that need to be considered. First, it was an observational study that we can't take part in patients' therapy, anemia management and patients' habit in their daily activity. Another one was hospital capacity of hemodialysis machines that influence in a number of hemodialysis patients.

\section{Conclusion}

Average rate of haemoglobin, FACIT and KDQOL were increased after one month anemia treatment using erythropoietin while average rate of KDQOL was different significantly. Erythropoietin can improve the QOL of CKD patients with routine hemodialysis.

\section{Compliance with ethical standards}

\section{Acknowledgments}

In data collection for this research, we acnowledge the assistances Sari Rahmadani, staf of Hemodialysis Unit Haji Adam Malik Hospital Medan. The researcher thanked Director of Haji Adam Malik Hospital Medan and Director of Medan Health Polytechnics.

\section{Disclosure of conflict of interest}

All authors declare that there is no conflict of interest.

\section{Statement of informed consent}

"Informed consent was obtained from all individual participants included in this study"

\section{References}

[1] Jha V, Garcia-Garcia G, Iseki K, Li Z, Naicker S, Plattner B, et al. Chronic kidney disease: global dimension and perspectives. Lancet. 2013; 382: 260-72.

[2] Somvanshi S, Khan NZ, Ahmad M. Anemia in chronic kidney disease patients. Clinical Queries: Nephrology I. 2012; 198-204.

[3] Lu WX, Jones-Burton C, Zhan M, Salzberg DJ, Moore J Jr, Fink JC. Survival benefit of recombinant human erythropoietin administration prior the onset of end-stage renal disease: variations across surrogates for quality of care and time. Nephron Clin Pract. 2005; 101: 79-86.

[4] Levin NW, Lazarus JM, Nissenson AR. National cooperative rHu erythropoietin study in patients with chronic renal failure - an interim report. The National Cooperative rHu Erythropoietin Study Group. Am J Kidney Dis. 1993; 22: 3-12.

[5] Naci H, Lissovoy G, Hollenbeak C, Custer B, Hofmann A, McClellan W, et al. Historical clinical and economic consequence of anemia management in patients with end-stage renal disease on dialysis using erythropoietin stimulating agents versus routine blood transfusions : a retrospective cost-effectiveness analysis. J Med Econ. 2012; 15: 293-304.

[6] Jelkmann W. Molecular biology of erythropoietin. Intern Med. 2004; 43: 649-59.

[7] Walters SJ. Quality of life outcomes in clinical trials and health-care evaluation: a practical guide to analysis and interpretation. John Wiley and Sons Ltd pub. 2009.

[8] Cella D, Yount S, Sorensen M, Chartash E, Sengupta N, Grober J. Validation of the functional assessment of chronic illness therapy fatigue scale relative to other instrumentation in patients with rheumatoid arthritis. J Rheumatol 2005; 32: 811-19.

[9] Webster K, Cella D, Yost K. The functional assessment of chronic illness therapy (FACIT) measurement system; properties, applications, and interpretation. Health Qual Life Outcomes. 2003; 1: 1-7. 
[10] Tennant KF. Assessment of fatigue in older adults: The FACIT-Fatigue Scale (Version 4). General assessment series from The Hartford Institute for Geriatric Nursing, New York, College of Nursing. 2012; 20: 1-2.

[11] Sihombing JP, Hakim L, Andayani TM, Irijanto F. Validation of Indonesian version of FACIT Fatigue Scale questionnaire in CKD patients with routine hemodialysis. IJCP. 2016; 5: 231-37.

[12] Singh AK, Szczech L, Tang KL, Barnhart H, Sapp S, Wolfson M, et al. Correction of anemia with epoetin alfa in chronic kidney disease. N Engl J Med. 2006; 355: 2085-98.

[13] Hansen RA, Chin H, Blalock S, Joy MS. Predialysis chronic kidney disease: evaluation of quality of life in clinic patients receiving comprehensive anemia care. Res Social Adm Pharm. 2009; 5: 143-53.

[14] Lee BO, Lin CC, Chaboyer W, Chiang C-L, Hung CC. The fatigue experiences of hemodialysis patients in Taiwan. J Clin Nurs. 2007; 16: 407-13.

[15] Kazemi M, Nasrabadi AN, Hasanpour M, Hassankhani H, Mills J. Experience of Iranian persons receiving hemodialysis: a descriptive, exploratory study. Nurs Health Sci. 2011; 13: 88-93.

[16] Murali R, Sathyanarayana D, Muthusethupathy MA. Assessment of quality of life in chronic kidney disease patients using the kidney disease quality of life-short formTM questionnaire in Indian population: a community based study. Asian J Pharm Clin Res. 2015; 8: 271-4.

[17] Sklar AH, Riesenberg LA, Silber AK, Ahmed W, Ali A. Post dialysis fatigue. Am J Kidney Dis. 1996; 28: 732-36.

[18] Rocco DG, Mercieri A, Yavuzer G. Multidimensional health-status assessment of chronic hemodialysis patients: the impact of quality of life. Eura Medicophys. 2006; 42: 113-19.

[19] Sklar AH, Newman N, Scott R, Semenyuk L, Schultz J, Fiacco V. Identification of factor responsible for postdialysis fatigue. Am J Kidney Dis. 1999; 34: 464-70.

[20] Wang SY, Zang XY, Liu JD, Gao M, Cheng M, Zhao Y. Psychometric properties of the functional assessment of chronic illness therapy-fatigue (FACIT-Fatigue) in Chinese patients receiving maintenance dialysis. J Pain and Symptom Management. 2015; 49: 135-42. 